\title{
The opioid and pain intensity index-A proposal
}

Emmanuel Bäckryd

The self-archived postprint version of this journal article is available at Linköping University Institutional Repository (DiVA):

http:/ / urn.kb.se/ resolve?urn=urn:nbn:se:liu:diva-153495

N.B.: When citing this work, cite the original publication.

Bäckryd, E., (2019), The opioid and pain intensity index-A proposal, Acta Anaesthesiologica

Scandinavica, 63(1), 133-134. https:// doi.org/ 10.1111/ aas.13252

Original publication available at:

https:// doi.org/ 10.1111/aas.13252

Copyright: Wiley

http:// eu.wiley.com/WileyCDA/ 
The Opioid and Pain intensity Index (OPI) - a proposal

\section{Emmanuel Bäckryd}

Sir,

When assessing the effect of pain interventions over time, one is sometimes confronted with the problem of evaluating the combined outcome of lessened pain intensity and diminution in doses of concomitant systemic opioids. Often, both outcomes are reported separately, ${ }^{1}$ or one of them can be chosen as primary outcome and the other as secondary. ${ }^{2}$ Here, the Opioid and Pain intensity Index (OPI) is proposed as a 0-10 metric that combines Numerical Rating Scale (NRS) 0-10 pain intensity data with the dose of opioids expressed as mg per day of Oral Morphine Equivalents (OME).

First, OME doses are converted to OME Category (OMEC) 0-10, as follows:

- OME 0-99 $\mathrm{mg} \rightarrow$ OMEC 0

- OME 100-199 mg $\rightarrow$ OMEC 1

- Etc...

- OME 900-999 mg $\rightarrow$ OMEC 9

- $\mathrm{OME} \geq 1000 \mathrm{mg} \rightarrow$ OMEC 10

Hence, we now have two ordinal 0-10 scales, NRS and OMEC. Now, imagine a twodimensional space with orthogonal axes, one representing NRS and the other OMEC. Each patient will be a point in this plot, and the distance from the origin of the plot to each patient

will be expressed by applying a simple Pythagorean Theorem: $\left.\sqrt{\left(N R S^{2}\right.}+O M E C^{2}\right)$. Each patient will then, on the basis of NRS and OMEC, be characterized by a value ranging from 0 to $\sqrt{200}$, i.e., a $0-14.14$ scale. This metric can easily be normalized to a more familiar 0-10 scale, which will be OPI. Hence:

$\left.O P I=\frac{\left.\sqrt{\left(N R S^{2}\right.}+O M E C^{2}\right)}{\sqrt{200}} * 10=0.7071 * \sqrt{\left(N R S^{2}\right.}+O M E C^{2}\right)$

Applying OPI to previously published data on the effect of bupivacaine-based intrathecal analgesia (ITA) on severe resting cancer pain (case series without control group), ${ }^{1}$ OPI before the intervention was compared to OPI one week after the intervention, providing a single metric for the combined effect of the intervention over time on both NRS and OME. 
Expressing data as median (interquartile range) and using non-parametric statistics for related samples, OPI went from 6.0 (4.9-7.4) to 2.1 (1.2-2.9), P<0.001, Fig. 1.

A far from self-evident presupposition for OPI is that NRS and OME are equally important. It is also important to acknowledge that the same OPI value can mirror very different clinical situations; the point with OPI is to be able to measure the combined effect of e.g. invasive interventions such as ITA or neurolysis on both NRS and OME on patients with advanced cancer. Compared to e.g. the equianalgesic score described by Mercadante et al, ${ }^{3} \mathrm{OPI}$ is arguably easier to interpret, not least because of the familiar 0-10 metric.

Of course, a simpler alternative to OPI would be to compute the mean of NRS and OMEC, i.e., $\frac{N R S+O M E C}{2}$; such a Simplified OPI (SOPI 0-10) would not geometrically express the "true" distance to the origin of the above-mentioned plot, but it is of course much more simple to compute and would perhaps therefore be preferable for pragmatic reasons. The key to both OPI and SOPI is the transformation of OME into OMEC.

Emmanuel Bäckryd

Pain and Rehabilitation Centre

Linköping, Sweden 


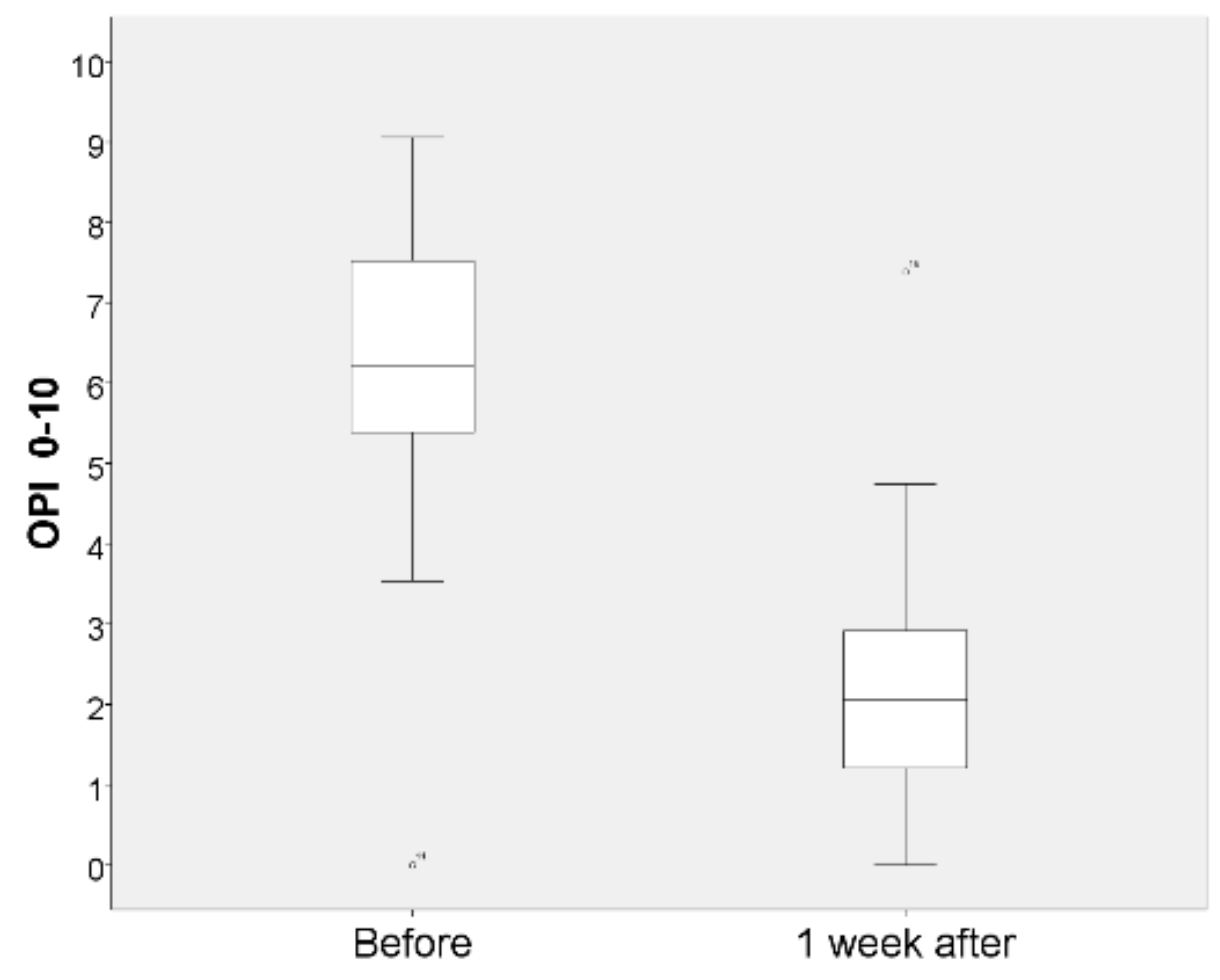

Figure 1: Opioid and Pain intensity Index (OPI) before and 1 week after start of bupivacaine-based intrathecal analgesia for intractable cancer pain 


\section{References}

1. Bäckryd E, Larsson B. Movement-evoked breakthrough cancer pain despite intrathecal analgesia: A prospective series. Acta Anaesthesiologica Scandinavica 2011;55:1139-46.

2. $\quad$ Myhre M, Romundstad L, Stubhaug A. Pregabalin reduces opioid consumption and hyperalgesia but not pain intensity after laparoscopic donor nephrectomy. Acta Anaesthesiol Scand 2017;61:1314-24.

3. Mercadante S, La Rosa S, Villari P. CT-guided neurolytic splanchnic nerve block by an anterior approach. J Pain Symptom Manage 2002;23:268-70. 